Short Communications

\title{
WHAT EMPOWERED COMMUNITY CAN DO FOR TB CARE? EXPERIENCE FROM INDIA
}

\author{
Prasad BM', Rao GS², Raipai J2, Reddy KK², Sharma D², Danial S², Kumar K², Gupta BD², Mohanty \\ $\mathbf{S}^{1}$,Chadha SS $^{1}$
}

${ }^{1}$ The International Union Against Tuberculosis and Lung Disease

${ }^{2}$ The Catholic Health Association of India

\begin{abstract}
The community engagement strategies of Tuberculosis programmes prioritized on increasing case finding. There are limited evidences on - what an empowered community can do for Tuberculosis care? An innovative community empowerment model was developed and implemented in districts of India as "District Tuberculosis Forum" (DTF) under Project Axshya to engage and empower community. The paper here describes the contributions made by empowered forum members. We collected quantitative data from 77 districts for activities conducted during June 2013 to July 2014. The analysis is focused on activities conducted within patient centric, community and programme centric approaches. Empowered community members sensitized over $9000 \mathrm{~TB}$ patients on their rights and responsibilities and generated resources to support nearly 700 patients. The model is promising with key stakeholders at district level coming forward to get involved in activities supporting Tuberculosis prevention and care with an aim to END - TB.
\end{abstract}

Key Words:_Community Empowerment, Patient Centric approach, District Tuberculosis Forum, Project Axshya

\section{INTRODUCTION}

Community is the central focus of programmatic intervention and key strategy to increase universal access to healthcare. Globally, the programmatic approaches are suggestive of having community participation or per-se community engagement aimed at outreach activities. ${ }^{1}$ In Tuberculosis programme, community engagement strategies prioritized mainly on increasing case finding, disseminate information about Tuberculosis and engage volunteers as DOTS providers.

The World Health Organization (WHO), ENDTB strategy and programme guidelines of India,

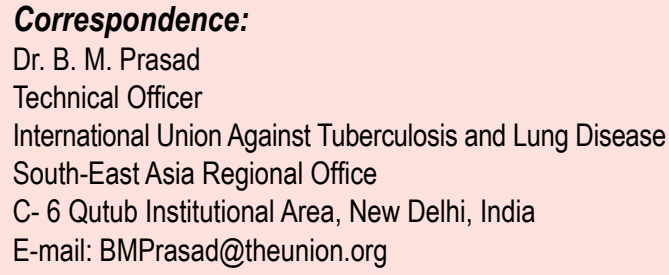

also emphasize on need to engage and empower communities for TB care. ${ }^{2,3}$ Various modalities are outlined for engaging and empowering, however, limited is known on what empowered communities could do. An empowerment model was designed to identify, sensitize, engage and empower key stakeholders at district level by constituting a forum christened as "District Tuberculosis Forum" (DTF). This forum is constituted with support from Project Axshya (A Global Fund TB grant to India). ${ }^{4}$ The paper here describe the contributions made by the empowered DTF members in India.

\section{METHODOLOGY}

District level project staff, encouraged identified key-stakeholders to be part of DTF and sensitized members on "patient -charter" of WHO to interact with patients on one-to-one basis ("patient centric approach") and to empower them about patients' rights and responsibilities. ${ }^{5}$ Patient empowerment is one of the core strategy of this model with an aim to have a positive treatment outcome. ${ }^{6}$ 
Community level participation of forum members ("community centric approach" to empower communities) is expected in project activities like local community meetings, where members inform about TB care and address issues related to "stigma" and or mobilize resources to support needy patients. ${ }^{7}$

This loop is completed by integrating empowered community to support the programme ("programme centric approach"). Forum members document observations related about programme that are limited to; visiting houses of TB patients who are recently diagnosed or irregular on treatment provide them with counselling support and social support. Forum members also visit the healthcare facility where TB services are provided, to conduct social or community monitoring and address any issue that cause hinder in providing the services.

In this paper we have used quantitative data for activities conducted by DTF members during June 2013 to July 2014that were available from 77 out of 96 districts under the preview of implementation partner Catholic Health Association of India (CHAl). ${ }^{4}$ The analysis of activities conducted were grouped under "patient centric approach", "community centric approach" and "programme centric approach" within the framework of Advocacy, Communication and Social mobilization (figure 1). Ethical approval was not sought as the data used do not have any patient identifiers or other individual identifiers and the study did an analysis of record review of available or reported data from the project.

\section{RESULTS}

About Forum members: Out of 77 DTFs reports analyzed, $58(75 \%)$ forums hadrepresentation of TB patients. Representation from local leaders and print media was seen in $55 \%$ of forums. Majority of DTF (in 72 districts) had representation from civil society (Table 1).
Patient Centric Approach: A total of 9,732 TB patients were sensitized on "patient-charter". During this sensitization process members addressed the issues raised by TB patients and communicated to programme officers. Apart from sensitization, forum members from 49 districts had conducted home visits to meet 480 TB patients to counsel family members and patients. In addition, provided nutritional support to 663 TB patients (reported from $75 \%$ of forum) and 100 Multi-DrugResistant (MDR) TB patients. This activity was supported through self-contribution by members in $64 \%$ of districts.

Community Centric Approach: Community centric approach showed participation of members (in $90 \%$ of DTFs) in community awareness programmes organized by the project. Members discussed about Tuberculosis transmission, prevention, treatment and care (in $65 \%$ of DTFs) in these meetings.

Empowered community members advocated for Nutritional support to patients (in $75 \%$ of 77 DTFs) with district level administrative authorities. These efforts led to policy revisions and one such example of policy revision is documented from the state of Kerala, India - to support a million plus poor TB patients. (Box 1).

Programme Centric Approach: The advocacy efforts of members focused on ensuring examination and exemption of User Fees, for presumptive TB referrals/sputa from community (in all 77 districts). Other advocacy efforts reported were - behaviour change among laboratory technicians (in 6 districts), recruitment of doctors (in two districts) and new diagnostic centers at government facilities (in four districts). Members also reviewed about availability of medicines at government facilities and with TB patients during their community visits (in 14 districts); including retrieval of lost to followup TB patients to programme (in 8 districts) (Table 1). 


\begin{tabular}{|c|c|c|c|}
\hline S. No. & Indicator & Number & Additional information \\
\hline \multicolumn{4}{|c|}{ Composition of DTF members (Districts) } \\
\hline A & $\begin{array}{l}\text { Non-government organization (NGO) } \\
\text { representation }\end{array}$ & 72 & \\
\hline B & TB patient as key stakeholder & 58 & $\begin{array}{l}\text { In } 75 \% \text { districts included TB patient as key stakeholder to share their } \\
\text { experience of being a "TB patient"during community/patient meetings. }\end{array}$ \\
\hline C & Social Worker & 51 & \multirow{7}{*}{$\begin{array}{l}\text { Multiple representation of key stakeholders were part of DTF. Each } \\
\text { stakeholder assumed respective role within the model. Others, } \\
\text { included, volunteers, community health workers, local business men, } \\
\text { philanthropies etc }\end{array}$} \\
\hline D & Local print media & 42 & \\
\hline $\mathrm{E}$ & Local Politician & 42 & \\
\hline $\mathrm{F}$ & Lawyer & 32 & \\
\hline G & HIV infected community & 35 & \\
\hline $\mathrm{H}$ & Private Doctors & 10 & \\
\hline \multirow[t]{2}{*}{1} & Others & 53 & \\
\hline & Total & 77 & \\
\hline \multicolumn{4}{|c|}{ Patient centric approach to empowerment (Patients) } \\
\hline a & Patient sensitization on patient charter & 9732 & $\begin{array}{l}\text { Patients were sensitized on "rights and responsibility" by one of the } \\
\text { member - mainly the chairman of TB forum group with support from TB } \\
\text { patient. }\end{array}$ \\
\hline b & Home visits by DTF members & 480 & $\begin{array}{l}\text { Counselling of patients on DOTS and their family members about TB } \\
\text { prevention and care. }\end{array}$ \\
\hline c & Nutritional support to patients on DOTS & 663 & $\begin{array}{l}\text { Locally generated resources, through contributions from community } \\
\text { members. DTF members also contributed to nutritional support. }\end{array}$ \\
\hline$d$ & Nutritional support to MDR-TB patients & 100 & Major contribution from private practitioners (doctors). \\
\hline \multicolumn{4}{|c|}{ Community centric approach to empowerment (Districts) } \\
\hline a & $\begin{array}{l}\text { DTF members participation in } \\
\text { community meetings }\end{array}$ & $58(75 \%)$ & $\begin{array}{l}\text { Mainly meeting with PRI members, village functionaries to sensitize on } \\
\text { TB prevention and care. }\end{array}$ \\
\hline b & $\begin{array}{l}\text { DTF members organising mid-media } \\
\text { campaign }\end{array}$ & $58(75 \%)$ & $\begin{array}{l}\text { Announcements in villages about "key messages" of TB prevention and } \\
\text { care. }\end{array}$ \\
\hline c & Advocacy for TB pension schemes & n.a & $\begin{array}{l}\text { Million plus poor TB patients supported in the state of Kerala. Similar } \\
\text { efforts are underway in other states. }\end{array}$ \\
\hline \multicolumn{4}{|c|}{ Programme centric approach to empowerment (Districts) } \\
\hline a & Facilitate services for TB patients & 6 & DTF members advocated for exemption of User Fees at public facilities \\
\hline b & $\begin{array}{l}\text { Ensuring availability of medicines to } \\
\text { TB patients }\end{array}$ & 14 & $\begin{array}{l}\text { DTF members reviewed availability of medicines at DOTS center and } \\
\text { at Tuberculosis units. }\end{array}$ \\
\hline c & Feedback on programme performance & 19 & $\begin{array}{l}\text { Members provided feedback about the performance of programme to } \\
\text { respective programme officers. }\end{array}$ \\
\hline
\end{tabular}

\section{Box I. Pension schemes for tuberculosis patients: An advocacy effort from TB forum Members of Kerala}

Kerala is one among first the states to introduce financial support scheme for TB patients in 1963. The utilization of scheme was abysmally low due to lack of information. Information about the scheme was known following revisions in 2010 to Rs 300 per month (USD 4.8) and subsequent revisions to Rs 525 per month in 2012 and to Rs 800 in 2013 (USD 13). Revisions in monetary terms did not follow revisions in inclusion criteria. Any family to avail the scheme need to be in the annual income cut-off of Rs 2400 i.e, USD 39. Project Axshya team sensitized DTF members about the issue and a channel of advocacy efforts were initiated.

The advocacy efforts led to acceptance of government for revisions in inclusion criteria. The government proposed decision for revisions in front of state elected representatives, to as "eligibility on annual income from Rs 2400 to Rs 100,000 (USD 1613) and increase in pension amount to Rs 1000 (USD 16). Both the proposals were accepted and about Rs $1,651,000$ (USD 26,630) is earmarked by government of Kerala in the current financial year. The efforts of DTF supported nearly 300 patients from 26 Taluks (sub-divisions of the district). The resolution will support all poor TB patients of the state in years to come.

Source: Jinesh Lal, Joltin C, Gadala Srinivasa, Krithika, Banuru Muralidhara Prasad, Tomi Thomas, Pension schemes for tuberculosis patients: An advocacy effort from TB forum members of Kerala, India, $45^{\text {th }}$ World Lung Conference, Barcelona Spain, $28^{\text {th }}$ October to $1^{\text {st }}$ November 2014. 


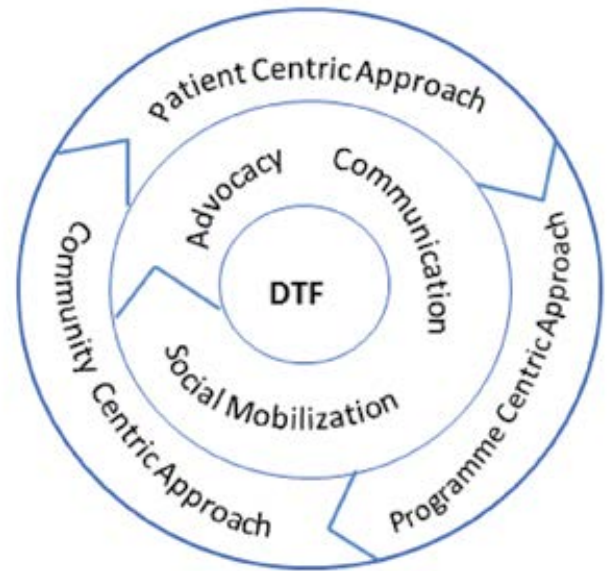

Figure 1. Diagrammatic representation of DTF Empowerment Model

\section{DISCUSSION}

The "District Tuberculosis Forum" -a community empowerment model is an innovative model of Project Axshya. Resources from the project supported sensitization of DTF members on "patient charter", organize quarterly meetings of members and supported home visits. This model has close resemblance to "TB patients' empowerment and involvement" described by Jean Macq in 2007 where empowered TB patient take control of own health by involving key stakeholders from community. ${ }^{6}$ One of the key stakeholder in our study is TB patient who were involved to share their experience with community. Similar experience is documented from a rural district of Ethiopia where patient based support groups are created to support the programme. ${ }^{8}$

The study has demonstrated that by enhancing capacities of key stakeholders in community, a holistic community empowerment model could be developed for TB care. At the policy level the model could be envisaged as a social-capital that bridge community-system- programme to achieve Universal Healthcare Coverage for TB services in India and elsewhere. ${ }^{9}$ In this study we included activities that could be documented and quantified; other qualitative discussions with community/ programme had limited documentation to be included.

\section{CONCLUSION}

The study is a brief description of activities focused at patient-community-programme centric approach that an empowered community through an organized forum - like DTF could perform. The model is promising with key stakeholders at district level coming forward to get involved in activities supporting Tuberculosis prevention and care with an aim to END -TB.

Acknowledgements: We would like to acknowledge the contribution of District level Project staff of Catholic Health Association of India (CHAl) and members of District Tuberculosis Forum.

Author Contribution: BMP conceptualized the paper, collated the information and wrote the paper. GSR implemented the project and reviewed manuscript. JR, DS, KKR, KK, SD, BDG, coordinated for implementation, and collected data. SC and SM conceptualized DTF model, reviewed and approved the manuscript.

Conflict of Interest: None declared.

\section{REFERENCES}

1. WHO. Engage-TB:Integrating communitybased tuberculosis activities into the work of nongovernmental and other civil society organizations. Geneva: WHO; 2013.

2. WHO. Global strategy and targets for Tuberculosis prevention , care and control after 2015. Geneva: WHO; 2013.

3. India Go. National Strategic Plan (2012-2017). New Delhi: Directorate of Health Services, Ministry of Health and Family Welfare, Central TB Division; 2012.

4. Union T. Project Axshya. [Online].; 2011 [cited 2013 Jan 10. Available from: "http://www. axshya-theunion.org/axshya" http://www.axshyatheunion.org/axshya .

5. WHO. The patients charter for Tuberculosis care:Patients rights and responsibilities. Geneva: WHO;2006.

6. Macq J, Torfoss T, Getahun H. Patient empowerment in tuberculosis control: reflecting on past documented experiences. Tropical Medicine and International Health. 2007 July;12(7):873-885.

7. Laverack $\mathrm{G}$, Wallerstein $\mathrm{N}$. Measuring community empowerment: a fresh look at organizational domains. Health Promotion International. 2001;16(2):179-185.

8. Getahun H, Maher D. Contribution of 'TB Clubs' to tuberculosis control in rural district in Ethiopia. International Journal of Tuberculosis and Lung Disease. 2000;4(2):174-178.

9. Ogden J, Morrison K, Hardee K. Social capital to strengthen health policy and health systems. Health Policy and Planning. 2014;29(8):10751085. 